\title{
THE EFFECT OF TeXt Authenticity ON THE PERFORMANCE OF IRANIAN EFL STUDENTS IN A C- TEST
}

\author{
Karen Kow Yip Cheng \\ kowyc@um.edu.my \\ Amir BiglarBaygi \\ Mesod Solaymani \\ University of Malaya
}

\begin{abstract}
As part of growing efforts to understand factors affecting c-test this study aims to investigate the effect of text authenticity on the performance of Iranian EFL students in a $\mathrm{C}$-Test. The C-Test is an integrative testing instrument that measures overall language competence, very much like the cloze test. In this study the rule of two has been applied: "the second half of every second word has been deleted, beginning with the second word of the second sentence; the first and last sentences are left intact" (Katona and Dornyei 1993: 35). The research involves 60 college students in their third year, majoring in English Literature at Ershad-Damavand College. This group were randomly selected applying multi-stage sampling. Since the present study intended to investigate the role of two different formats, i.e. authentic and inauthentic texts (text translated from Persian into English), two different tailored C-Tests were made to measure and compare the performances of the participants. Two C-Tests, one with Authentic Text and the other, with Inauthentic Text were administered to this homogenized group comprising 30 subjects. The findings of this study suggest that authenticity has an effect on the performance of learners in c-tests and we should control this variable while devising a ctest.
\end{abstract}

Key words: C-Tests, Authentic texts, Inauthentic texts, Test method facets

\section{Introduction}

The present study was conducted to investigate the effect of text authenticity on the performance of Iranian EFL college students in a C-Test. The C-Test is an integrative testing instrument that measures overall language competence, very much like the cloze test. In this study the rule of two has been applied: the second half of every second word has been deleted, beginning with the second word of the second sentence; the first and last sentences are left intact Katona and Dornyei 1993: 35). 60 college students in their third year, majoring in English Literature were randomly selected applying multi-stage sampling in which first a national sample of college districts in Iran stratified by major was obtained. Later on, within selected districts, Tehran colleges were selected using 
simple random sample technique and within colleges in Tehran, Ershad-Damavand College was selected. Further, within English Literature classes of this college, a simple random sample of students was carried out (Trochim, 2006). To ensure the homogeneity of the subjects in this study an IELTS exam was carried out and 30 students having scored one standard above and below the mean were selected for the purposes of this study. Since the present study intended to investigate the role of two different formats, i.e. authentic and inauthentic texts (text translated from Persian into English), two different tailored $\mathrm{C}$-Tests were made to measure and compare the performances of the participants. Two C-Tests, one with Authentic Text and the other, with Inauthentic Text were administered to this homogenized group comprising 30 subjects. Data were analyzed through matched t-test formula due to having one group of students with two different tasks and hoping to compare their performance on the tasks which are inauthentic and authentic C-Tests. The findings indicated a significant relationship between text authenticity and the performances of the participants in the C-Tests. Founded on the results of this study, one of the most crucial aspects of test method in CTests can be regarded as text authenticity (native/target language presentation). This aspect of test method has been recognized by Bachman (1990) as a crucial aspect of test method and the present study provides evidence for such an effect caused by the nature of language presentation on C-Tests.

\section{The C-Test}

The C-Test is a teacher friendly way of testing language proficiency. In the 1980s this measuring tool for placement testing was introduced (Katona and Dornyei 1993). The Ctest was developed in Duisburg by Christine Klein-Braley and Ulrich Raatz. Although it is known, it is not widely applied. This is due to the fact that, to some extent, the quality of the test depends on the input of the texts (Baten and Leuven, 2004).

The C-test is an integrative testing instrument that measures overall language competence, very much like the cloze test. It consists of four to six short, preferably authentic texts in the target language, to which "the rule of two" has been applied. The rule of two is where the second half of every second word is deleted, beginning with the second word of the second sentence; the first and last sentences are left intact. If a word has an odd number of letters, the "bigger" part is omitted, e.g. proud becomes pr-. Oneletter words, such as I, are ignored in the counting. The students' task is to restore the missing parts. In a typical C-Test there are 100 gaps, that is, missing parts. Only entirely correct restorations are accepted (Klein-Braley, 1994 and 1997). An example of such a C-test is shown below:

One cool autumn evening, Bob L., a young professional, returned home from a trip to the supermarket to find his computer gone. Gone! All so- of cr- thoughts ra- through h- mind: $\mathrm{H}-$ it be- stolen? H- it be- kidnapped? H- searched h- house f- a cl- until h- noticed a sm- piece oprintout pa- stuck un- a maga- on h- refrigerator do-. His he- sank a- he re- this sim- message: can't continue, file closed, bye.

(Katona and Dornyei 1993: 35) 


\section{Selection of Texts: The Nature of Input}

The C-Test comprises four to six short authentic texts, each complete as a sense unit in itself. Since C-Tests consist of different short texts, the selection of these texts (short passages) or input is of great importance and has been the subject of various investigations in order to make these tests more appropriate and less biased (McBeath, 1990).

Bachman (1990) proposed the test method facets in the book entitled "Fundamental Considerations in Language Testing". The test method facets are the variables affecting the overall performance of the testee and should be taken into account while constructing a test and interpreting the results of the test (Kobayashi, 2002). Bachman (1990) classifies test method facets into five categories: 1) testing environment; 2) test rubrics; 3 ) the nature of the input; 4) the nature of the expected response; and 5) the interaction between the input and the response. According to Bachman, these factors can affect test performance; it is important for testers to be aware of their influences and, if possible, minimize them. This study focuses on the third of these facets. "The nature of the input", that is, the materials presented to test takers. This was chosen as the main variable of the study because reading materials constitute a very important factor in reading comprehension tests. Background knowledge, for example, is a well-researched area (see for example: Alderson and Urquhart 1983, 1985a, 1985b; Bernhardt 1991; Carrell and Eisterhold 1983; Clapham 1996; Johnson 1981, 1982; Mohammed and Swales 1984; Salager-Meyer 1991; Steffensen and Joag-Dev 1984; Steffensen, Joag-Dev and Anderson, 1979; Ulijn and Strother 1990). Of the various factors, the choice of texts with a focus on authentic versus inauthentic was chosen for this investigation. This decision was based on an extensive literature survey of previous studies on text characteristics, naturalness of the text and readability (e.g. a series of studies by Beck and his colleagues, e.g. 1982, 1984, 1989, 1991, 1995; Britton, Van Dusen, Gulgoz and Glynn, 1989; Davison and Kantor 1982; Duffy and Kabance 1982; Duffy et al., 1989; Graves et al., 1988 and 1991; Klare 1985; Olsen and Johnson 1989; Reder and Anderson 1980; Urquhart, 1984).

Followed by Bachman's model (1990 and 1995), a large number of studies such as Kobayashi (2002a, 2004, 2005) have endorsed the method facets in reading comprehension tests and cloze tests. Most of the studies manipulated "the nature of the input" and "the nature of the expected response" while the former refers to the materials presented to test takers i.e. authentic/inauthentic, text structure ,etc. the latter suggests the type of answers you expect from the testee, i.e. open-ended questions, cloze tests, etc. For instance, Kobayashi $(2004,2005)$ maintains that there is a systematic relationship between the students' test performance and the effects of and the 'nature of the expected response', while the nature of input in testing refers to 'test organization' and 'test method characteristics', Kobayashi (2002a: 197) hypothesized that different 'text types' in reading comprehension tests can impinge on the test organization and thereupon the test takers' performance. Likewise, Harrison and Salinger (1998) alongside Koberl and Sigott's (1994) restate the significant role of text type to gauge reading comprehension ability of learners through regular reading tests.

From another perspective, there are a large number of empirical studies dealing with text authenticity and translation. Studies such as Sigott (1995), Gellerstam (1996), 
Laviosa-Braithwaite (1997) and Mauranen (2000) which carry in substance the same theme suggest that there authentic and translated texts relative drastically differ in number of lexical, grammatical and even pragmatic elements. For instance, Mauranen's (2000) findings on the relative under representation of discourse markers with highly TL-specific pragmatics can also be taken to support the general idea of inauthentic texts deficiency or as Sigott (1995: 47) stated, "translation creates different texts". Furthermore, these differences can denote Widdowson's (1983) notion of 'Authenticity Stimulus'. Widdowson comments on the notion of "authenticity" as follows:

An authentic stimulus in the form of attested instances of language does not guarantee an authentic response in the form of appropriate language activity .... we should retain the term 'authenticity' to refer to activity (i.e. process) and use the term 'genuine' to refer to attested instances of language (i.e. product).

(Widdowson 1983: 30)

Widdowson (1983) highlights the fact that the very notion of authenticity is open to debate. An authentic stimulus as he points out may well lead to an inauthentic response. In other words, the term 'authentic' is ambiguous and may lead to further ambiguity. Widdowson therefore recommends that the term be used to refer to attested instances of language produced by native speakers for a normal communicative purpose. In this sense it refers to naturalistic textual data. But the term can be used, quite legitimately, to refer to the communicative activity of the language user, to the engagement of interpretative procedures for making sense, even if these procedures are operating on and with textual data which are not authentic in the first place. As pointed out earlier, an authentic stimulus in the form of attested instances of language does not guarantee an authentic response in the form of appropriate language activity. At this juncture it should be emphasized that in this study 'authentic' texts were chosen based on Widdowson's interpretation mentioned earlier in this section.

\section{The Present Study}

The present study sets out to find whether in c-tests converting text type from authentic to inauthentic produce any effect on testees' performance. This investigation scaffolds on Bachman's (1995) contention concerning test method characteristics (facets). It is Bachman, who contended that factors affecting the test-taker's performance are multifaceted and thence crucially important for test designers to be attentive to the possible effects of these factors and give utmost attention to minimize these effect to a feasible extent and thus elicit the actual performance of the testee.

It is noteworthy that c-tests were, initially, developed to overcome the perceived weaknesses of cloze test. The C-test was developed as a modification of the cloze test which is a widely used language proficiency testing instrument. The cloze test is more favored due to the ease of constructing the test coupled with its high reliability and validity. Unlike the C-test, the cloze test consists of a longer text of which every fifth to tenth complete word is left out (Klein-Braley and Raatz, 1984).

The C-test offers considerable advantages compared with the cloze test which are listed as follows: 
1. As students are confronted with a variety of short passages, a better sampling of content areas is possible. Also, a person with special knowledge in a certain field does not have an unfair advantage.

2. By "damaging" every second word, we can obtain a more representative sample of all the different language elements in the text than in the cloze, where normally only every fifth or sixth word is left out.

3. Many more items can be included in much shorter texts, making the test less timeconsuming for the students than the cloze.

4. Unlike the cloze test, scoring is easy and objective, as there is only one acceptable solution in most cases.

5. As a rule, students actually like doing C-tests, whereas the cloze test is one of the most frustrating test types for learners.

(Katona and Dornyei 1993: 35)

Following this brief prelude to the c-test, it should be noted that Bachman's model (1990 and 1995) and considering 'method facets' can play an important role to enhance the efficacy of the c-test. One of these aspects in testing is "the nature of input" Kobayashi (2004a: 59) holds that 'the nature of input' in the reading materials presented to test takers, is an influential factor in reading comprehension tests. Furthermore, a cluster of studies on text characteristics and text organization of reading comprehension tests was carried out by Bachman (1995); Fountas and Pinell (2001); Johns (1997); Kobayashi (2002a, 2004, 2005) and Paltridge (1996). This cluster of studies illustrate that the text types is liable to influence the students performance in reading comprehension tests; thus, different 'text types' have significant effects on reading comprehension which leads to alteration in the testee's performance. Meanwhile, Brantmeier (2005); Klein-Braley (1994); Nakamura (1998); Sigott (1995); Sigott and Koberl (1993); Woolls and King (1999) in their studies highlighted the significant differences between authentic, inauthentic and quasi authentic texts. Woolls and King (1999), to cite as an instance, argues that different inter-relationships between an authentic text and possible translated versions of it. Besides, Woolls and King (1999) maintain that all translated texts substantially vary in the features of layout and paragraphing and considerably differ in text encoding and information presentation.

One implication derived from this brief literature review is that the C-Tests is likely to be affected by text type. As Paltridge (2001) and Kobayashi (2002a) recurrently assert, text type is liable to bring about satisfactory or otherwise level of performance from the test-taker's part; Hence, the present study sets out to find whether text type, i.e. authentic vs. inauthentic, can affect the performance of EFL college students on the CTest. In other words, having considered Bachman's model for test method facets (1990, 1995) and subsequent empirical studies conducted concerning this model, it can be assumed that the authentic and inauthentic texts as one possible test method facet of the c-test are expected to influence the overall performance of Iranian EFL college students in a particular c-test. Therefore, the following question was proposed in this study:

Is there any significant relationship between the performance of EFL college students and the authentic and inauthentic texts on the C-Tests, while the level of language proficiency and difficulty level of the texts are controlled? 
Based on the formulated researched question, the following null-hypothesis was adopted:

There is no significant relationship between the performance of EFL college students and the authentic and inauthentic texts on the C-Tests, while the level of language proficiency and difficulty level of the texts are controlled.

\section{Method}

\subsection{Subjects}

The subjects participated in this study were 30 females aged 21-30 majoring in the English literature at Ershad Damavand College based in Iran. To assure homogeneity of students with regard to general English, a TOFEL test (Phillips, 2001) was administered to 60 participants through multi-stage sampling in which first a national sample of college districts in Iran stratified by major was obtained. Later on, within selected districts, Tehran colleges were selected using simple random sample technique and within colleges in Tehran, Ershad-Damavand College was selected. And, within English Literature classes of this college, a simple random sample of students was carried out (Trochim, 2006).

Considering the selection of participants, it should be noted that those who scored one standard above and below the mean were selected as the subjects of this study. The 40 remaining formed the participant group.

\subsection{Constructing the $\mathrm{C}$-Tests}

Due to the existence of two different texts (authentic vs. inauthentic), two miscellaneous tailored C-Tests were used in the research as follows:

a) Tailored C-Tests 1: the Authentic Text (AT)

b) Tailored C-Test 2: Inauthentic Text (IT)

Each of the above C-Tests comprised four sub-tests (short passages), for the purpose of text selection one readability formula, i.e. the Flesch Reading Ease Score (FRES) was applied. The estimated Flesch reading ease for the texts was 46.3, which is considered rather higher than the average difficulty level acknowledged by FRES (Flesch, 1948).

Adhering to the guidelines laid down by Katona and Dornyei (1993) and KleinBraley (1997), two C-Tests, each of them comprising four short texts (subtests) and each subtest with a number of mutilations, were constructed (refer to appendix I,II). To each C-Test "the rule of two" was applied: the second half of every second word was deleted, beginning with the second word of the second sentence; the first and last sentences were left intact. If a word had an odd number of letters, the "bigger" part was omitted, e.g., proud becomes pr. One-letter words, such as I, were ignored in the counting. The students' task was to restore the missing parts. 
In scoring the right-word-only scheme was used and no alternatives were accepted; in other words, only entirely correct restorations were counted as correct answers.

Considering the Selection of authentic and inauthentic texts in C-Test Passages it should be noted that adopting English Language textbooks that are written by non-native speakers of the language in Iran is a norm. Hence, there is a common trend in which L2 learners are exposed to many inauthentic translated texts written by non-native Iranians. In other words, there are some texts in English textbooks in Iran loaded with inauthentic texts (translated from L1 into English). The rationale behind is to avoid undesired acculturation. Therefore, for Iranian students having been exposed to inauthentic texts heavily loaded with many cultural notions of their L1, the text authenticity can play a major part in measuring their reading comprehension abilities through c-test. If that is the case, teachers should interpret the results of the c-test with more caution and test designers and textbook writers would also need to use more authentic texts bearing fewer loads of L1 thoughts and cultural points.

\subsection{Procedure}

According to the guidelines given by Klein-Braley (1997), two C-Tests, each of them comprising four short texts (subtests) and each subtest with a number of mutilations, were constructed (refer to appendix A, B). These C-Tests were piloted with 30 senior EFL students in IAU and the necessary changes and calculations made to achieve item characteristics, that is, item facility and item discrimination.

For sampling the population for the study, 60 senior college EFL students in English faculties of IAU were randomly selected. The standardized test of proficiency, i.e. TOEFL (Phillips, 2001) was administered to the 60 participants and the results were put on the normal curve. The participants with marks that fall in one standard deviation from above and below the mean were selected for in study.

Taking into consideration the purpose of the study in relation to texts (inauthentic vs. authentic texts), two C-Tests were developed. After controlling the reliability, validity, IF and ID of the C-Tests, they were administered to the target group of 30 respondents. Next scoring based on one correct-word-only was carried out. Finally data analysis was carried out in which the matched t-test was applied.

Due to the nature of the study, in which the relationship between text authenticity (independent variables) and EFL learners' performance on C-Tests (dependent variable) were investigated, the matched t-test was applied.

\subsection{Pilot Study}

For the purpose of validation and reliability of the c-tests, the early versions of the two $\mathrm{C}$-Tests were piloted with a sample group which comprised 30 participants enjoying characteristics similar to the target groups. The results of administrating these C-Tests were compared with the results of administrating the TOEFL test (criteria) to the same group of the testees. The scores of the newly developed tests were correlated with those of the proficiency test to evaluate the concurrent validity. 
Subsequent to estimating the validity of the two C-Tests, KR-21 method and Cronbach alpha were applied to compute the reliability of the c-tests. Estimated internal consistency measures (KR-21) and the results of Cronbach alpha formula revealed that all of the C-Tests enjoyed acceptable reliability values.

As mentioned earlier, to estimate the empirical validity of the two C-Tests, the Pearson product-moment correlation coefficients between the C-Tests scores and TOEFL test scores were calculated. Considering validity coefficients, the C-Tests of the present research seemed plausibly valid owing to the fact that their correlation coefficient with the TOEFL test scores exceeded .50.

\section{Results and discussion}

The study was based on the co-relational method, accordingly the difference between the means of each subject on both C-Tests (Authentic Vs. no authentic) were compared for statistical significance. The matched t-test was run in order to probe the null-hypothesis adopted in this research.

\subsection{Descriptive Statistics and Matched t-test}

The basic descriptive statistics including the calculation of mean, standard deviation, and minimum and maximum of test scores were performed for all the C-Tests used in the study, the results are as follows (Table 1):

Table 1: Descriptive Statistics of the C-Tests 1, 2,

\begin{tabular}{|c|c|c|c|c|c|c|c|}
\hline C-Tests & N & Range & Min. & Max. & Mean & Std. Dev. & Variance \\
\hline PGAT 1 & 30 & 48 & 41 & 89 & 61.26667 & 15.21 & 231.44 \\
\hline LGAT 3 & 30 & 30 & 27 & 57 & 39.83333 & 8.53 & 72.90 \\
\hline
\end{tabular}

The C-Tests means comparison showed that the participants had outperformed on C-Test 1 (non-authentic), i.e. the C-Tests that were made by utilizing the translated (Persian into English) texts. The participants` performances on C-Test 1, made from authentic English texts, were weaker than the other C-Test.

Table 2: t-observed value

\begin{tabular}{|c|c|c|c|c|c|}
\hline Source & Sum of Squares & DF & Mean Square & t-observed & Sig. \\
\hline TEXT & 3674.13 & 1 & 3674.13 & 28.62 & .000 \\
\hline
\end{tabular}

Considering the null hypothesis, the t-observed value reveals that the t-critical 28.62 is .000 , which is much lesser than the level of significance (0.05), i.e. the null hypothesis of the study is rejected and there is a significant relationship between the performance of Iranian EFL college students and the authentic and inauthentic texts in C-Tests. 


\section{Conclusion}

In view of the variables involved in the study, the English knowledge or competence of the students as the independent variable and the performance of the students as the dependent variable, the results of the present study indicated that text authenticity had a significant relationship with the performance of the testees in the C-Tests.

In particular, the results indicate the existence of a significant relationship between text authenticity and students performance on the C-Tests, which is harmonious with Nakamura's (1998) suggestion that in terms of text, the crucial facet of authenticity in the testing instrument and evaluating in the performance of the students should be borne in mind. Likewise, the research findings are also in congruity with the findings of Sigott's (1995) study which shows that translation creates different texts. Last but not least, the findings of this study is congruent with the assertion of Elmore and Headrick (2002: 131) that "the wording used in the translated version of an assessment does not undergo the same process of refinement as the wording used in the assessment written in the original language" and a translated text appears to be less difficult for the testee in view of the fact that the translation makes the text different from that of the original and the testee is more familiar with the background knowledge, non-native structures and choice of words.

From another perspective, the results of the present study provides solid evidence to Klein-Braley's (1994) suggestion that it is permissible to work with quasi-authentic texts when the authentic texts are too difficult for learners of a second or foreign language. Meanwhile, the findings of the present study support Ranalli's (2002) claim that in text selection for C-Tests, source and text difficulty are important variables. In other words, the results support the assertion of Klein-Braley and Raatz (1984: 135) who argued that "care must be taken not to place an undue burden on test takers' knowledge of the content matter".

Besides, the study showed a significant relationship between the performance of EFL learners on C-Tests and the authenticity of language used in the C-Tests passages. In other words, based on the findings of the present study, text authenticity can be viewed as test method facets in the C-Tests, which implies that contextual features of language that affect performance on language tests are specifically important in view of the fact that the facets may affect test takers' scores and thus jeopardize those students whose future academic career relies heavily on the results of suchlike tests and lessen the validity of our measuring tools.

Considering the purpose of language testing that according to Bachman and Palmer (1996: 341) is "to enable the tester to make inferences about test takers' ability to use language to perform tasks in a particular domain", the results of the present study in relation to authentic texts utilized in the C-Tests are likely to have implications in measuring the ability of the testee with more accuracy. In other words, it has been revealed that choice of text can be an important factor in designing the C-Test. The researcher is conscious of the fact that there are other factors affecting the C-Test and should be explored through further research in testing and evaluation. However, if the factors affecting the C-test are highlighted in some research in line with the present study, that can be a good contribution to language evaluation. Due to the fact that the CTest is an excellent testing method, as it provides a reliable and quick assessment of 
general language competence. It is therefore recommended that a good C-Test can cater for the following purposes:

- Selecting and placing students in appropriate groups

- Assessing their achievement at end-of-term exams by selecting several typical passages from the term's materials

- Testing certain grammar areas (e.g., tenses or word formation) by including texts that contain several examples of the structures in question

- Checking home reading or homework by taking passages from the texts the students had to work on

- Measuring the specialized knowledge of ESP groups by choosing suitable texts from their particular field of specialization

Before closing, it should be once more emphasized that the C-test is one of the most versatile test types and can be adapted to many different purposes. It is strongly recommended that practicing teachers incorporate the C-test into their everyday teaching and testing activities. Furthermore, should prevailing traditional reading comprehension tests are superseded with the c-tests, they can serve, on the one hand, as a better touchstone for EFL/ESL educators to evaluate reading comprehension ability of their learners and on the other hand can boost learners' ability to comprehend and outperform in prevailing traditional reading tests.

\section{References}

Alderson, J. C. and A. H. Urquhart. 1983. The effect of student background discipline on comprehension: Pilot study. In A. Hughes and D. Porter (eds) Current developments in language testing, (pp. 121-127). London: Academic Press.

Alderson, J. C. and A. H. Urquhart. 1985a. This test is unfair: I'm not an economist. In P. L. Carrell, J. Devine and D. Eskey (eds) Interactive approaches to second language reading, (pp. 168-182). Cambridge: Cambridge University Press.

Alderson, J. C. and A. H. Urquhart. 1985b. The effect of students' academic discipline on their performance on ESP reading tests. Language Testing, 2, 192-204.

Bachman, L. F. 1990. Fundamental considerations in language testing. Oxford: Oxford University Press.

Bachman, L. F. 1995. Fundamental Considerations in Language Testing: Third impression. Oxford: Oxford University Press.

Bachman, L. F. and M. Palmer. 1996. Conceptual bases of test development. Cambridge: Cambridge University Press.

Beck, I. L. , M. G. McKeown and E. W. Gromoll. 1989. Learning from social studies texts. Cognition and Instruction, 6, 99-158.

Beck, I. L., McKeown, M. G., Omanson, R. C. and Pople, M. 1984. Improving the comprehensibility of stories: The effects of revisions that improve coherence. Reading Research Quarterly, 19, 263-277.

Beck, I. L., McKeown, M.G., Sinatra, G. M., and Loxterman, J. A. 1991. Revising social studies text from a text processing perspective: Evidence of improved comprehensibility. Reading Research Quarterly, 26, 251-276. 
Beck, I. L., McKeown, M. G. and Worthy, J. 1995. Giving a text voice can improve students' understanding. Reading Research Quarterly, 30, 220-238.

Beck, I. L., Omanson, R. C. and McKeown, M.G. 1982. An instructional redesign of reading lessons: Effects on comprehension. Reading Research Quarterly, 17, 462481.

Bernhardt, F. B. 1991. Reading Development in Second Language: Theoretical, Empirical and Classroom Perspectives. New Jersey: Ablex Publishing Corporation

Brantmeier, C. 2005. Effects of Reader's Knowledge, Text Type, and Test Type on L1 and L2 Reading Comprehension in Spanish. The Modern Language Journal 89 (1), 37-53.

Britton, B.K., Van Dusen, L., Gulgoz, S. and Glynn, S.M. 1989. Instructional texts rewritten by five expert teams: Revisions and retention improvements. Journal of Educational Psychology, 81, 226-239.

Carrell, P. L. and Eisterhold, J. C. 1983. Schema theory and ESL reading pedagogy. TESOL Quarterly, 17, 553-573.

Clapham, C. 1996. The Development of IELTS: A study of the effect of background knowledge on reading comprehension. Cambridge: Cambridge University Press

Davison, A. and Kantor, R. 1982. On the failure of readability formulas to define readable texts: A case study from adaptations. Reading Research Quarterly, 17, 187 209.

Duffy, T.M. and Kabance, P. 1982. Testing a readable writing approach to text revision. Journal of Educational Psychology, 74, 733-748.

Duffy, T. M., Higgins, L., Mehlenbacher, B., Cochran, C., Wallace, D., Hill. C., Haugen, D., McCaffrey, M., Burnett, R., Sloane, S., and Smith, S. 1989. Models for the design of instructional text. Reading Research Quarterly, 24, 434-457.

Elmore, P. B. and Headrick, T. C. 2002. A Proposed Number Correct Scoring Procedure Based on Classical True-Score Theory and Multidimensional Item Response Theory. International Journal of Testing, 2(2), 100-112.

Flesch, R., 1948. A new readability yardstick. Journal of Applied Psychology. 32, 321333.

Fountas, I. and Pinell, G.S. 2001. Guiding Readers and Writers Grades 3-6: Teaching Comprehension, Genre, and Content Literacy. Portsmouth, NH: Heinemann.

Gellerstam, M. 1996. Translation as a source for cross-linguistic studies: Languages in Contrast. Lund: Lund University Press.

Graves, M.F., Slater, W.H., Roen, D., Redd Boyd, T., Duin, A.H., Furniss, D.W. and Hazeltine, P. 1988. Some characteristics of memorable expository writing: Effects of revisions by writers with different backgrounds. Research in the Teaching of English, 22, 242-280.

Graves, M.F., Prenn, M.C., Earle, J., Thompson, M., Johnson, V. and Slater, W.H. 1991. Improving instructional texts: Some lessons learned. Reading Research Quarterly, $26,110-132$.

Harrison, C. and Salinger, T. 1998. Assessing reading: Theory and Practice. London: Routledge.

Johns, A. 1997. Text, Role, and Context, Cambridge: Cambridge University Press.

Johnson, P. 1981. Effects on reading comprehension of language complexity and cultural background of a text. TESOL Quarterly, 15, 169-181. 
Johnson, P. 1982. Effects of reading comprehension of building background knowledge. TESOL Quarterly, 16, 503-516.

Katona, L and Dornyei, Z. 1993. C-test: A teacher friendly way to test language proficiency. English Teaching Forum, 31 (1), 35.

Klare, G. R. 1985. How to write readable English. London: Hutchinson.

Kobayashi, M. 2002a. Method effects on reading comprehension test performance: text organization and response format. Language Testing 19(2): 193-220.

Kobayashi, M. 2002b. Cloze tests revisited: Exploring item characteristics with special attention to scoring methods. Modern Language Journal, $86,571-586$.

Kobayashi, M. 2004. Investigation of test method effects: text organization and response format: a response to Chen, (2004). Language Testing, $21,235-244$.

Kobayashi,M. 2005. Ân investigation of method effects on reading comprehension test performance. Proceedings of the 4th Annual JALT Pan-SIG Conference., Tokyo, May 2005 (p.73) Tokyo, Japan: Tokyo Keizai University.

Koberl, J. and Sigott, G. 1994. Adjusting the C-Test difficulty in German. In Rudiger Grotjahn (Ed.), Der C-Test. Theoretische Grundlagenund praktische(pp.121-148). Anwoendungen, Bochum: Brockmeyer.

Klein-Braley, C. 1984. Advance prediction of difficulty with C-tests. In T. Culhane, C. Klein-Braley, and D. K. Stevenson (Eds.) Practice and problems in language testing . Proceedings of the Seventh International Language Testing Symposium of the IUS, Colchester, October 1983 (pp. 97-112). Colchester, England: University of Essex, Dept. of Language and Linguistics.

Klein-Braley, C. and Raatz, U. 1984. A survey of research on the C-test. Language Testing 1, 134-146.

Klein-Braley, C. 1997. C-Tests in the context of reduced redundancy testing: an Appraisal. Language Testing 14, pp. 47-84.

Klein-Braley, C. 1994. Language testing with the C-Test: A linguistic and statistical investigation into the strategies used by $\mathrm{C}$-Test takers, and the prediction of C-Test difficulty. Duisburg: Habilitationsschrift.

Laviosa-Braithwaite, S. 1997. The English Comparable Corpus (ECC): A resource and a methodology for the empirical study of translation. Manchester: UMIST.

Mauranen, A. 2000. Corpus-based Approaches to Translation, Strange Strings in Translated Language. A Study on Corpora. Helsinki: University of Tampere.

McBeath, N. 1990. C-Tests - some words of caution. English Teaching. Forum, 28, 4546.

Mohammed, M.A.H. and Swales, J.M. 1984. Factors affecting the successful reading of technical instructions. Reading in a Foreign Language, 2, 206-217.

Olsen, L.A. and Johnson, R. 1989. A Discourse based approach to the assessment of readability. Linguistics and Education, 1, 207231.

Paltridge, B. 1996. Genre and the language-learning classroom. Ann Arbor: University of Michigan Press.

Paltridge, B. 2001. Genre and the Language Learning Classroom. Pennsylvania State: University of Michigan Press.

Phillips, Deborah. 2001. Longman complete course for the TOEFL ${ }^{\circledR}$ Test: Preparation for the computer and paper tests (With answer key). New York: Pearson Education: 676. 
Reder, L.M. and Anderson, J.R. 1980. A comparison of texts and their summaries: Memorial consequences. Journal of Verbal Learning and Verbal Behavior, 19, 121 134.

Salager-Meyer, F. 1991. Reading expository prose at the post-secondary level: The influence of textual variables on L2 reading comprehension (a genre-based approach). Reading in a Foreign Language, 8, 645-662.

Sigott, G. 1994. Language test validity. AAAA- Arbeiten aus Anglistik und Amerikanistik, 19 (2), 287-294.

Sigott, G. 1995. The C-test: some factors of difficulty. AAA-Arbeiten aus Anglistik und Amerikanistik, 20 (1), 43-53.

Siong, K. 2004. Exploring the connection between the testing of reading and literacy, Journal of Language Studies, 4(1),78-88.

Steffensen, M.S. and Joag-Dev, C. 1984. Cultural knowledge and reading. In J.C. Alderson, and A.H. Urquhart, (Eds.), Reading in a Foreign Language (pp.48-61). London: Longman.

Steffensen, M.S., Joag-Dev, C. and Anderson, R.C. 1979. A cross-cultural perspective on reading comprehension. Reading Research Quarterly, 15, 10-29.

Trochim, W. M. 2006 The research method knowledge based. www.socialsearchmethod.net

Ulijn, J.M. and Strother, J.B. 1990. The effect of syntactic simplification on reading EST texts as L1 and L2. Journal of Research in Reading, 13, 38-54.

Urquhart, A. H. 1984. The effect of rhetorical ordering on readability. In J.C. Alderson, and A.H. Urquhart (Eds.), Reading in a Foreign Language (pp. 160 -175). London: Longman.

Widdowson, H. G. 1983. Learning purpose and language use. Oxford: Oxford. University Press.

Woolls, D. and P. King, P. 1999. Creating and using a multilingual parallel. Concordancer, Birmingham: The University of Birmingham. 


\section{Appendix A: sample C-test format with authentic texts Direction: Read the text below then restore the missing part of the words.}

I hear so many tales about how people have lost weight and kept it off. One story that I fo--- interesting tells of an act--- 5'6', 210-po----, 33-year-old woman. For me wh-- I found so intri---- about her story was the fa--- that she did wor---- regularly, but som------ was continuing to ga---- weight. My point is that bef---- you set go---, know who you are. I th--- at times peo---- set thems------- up by wanting som----- that is not a reflection of who they are or what rea---- they live in. The number one thing to remember before trying to jump into a lifestyle change is jumping into a lifestyle that you can live with.

\section{Appendix B: sample C-test format with Inauthentic texts Direction: Read the text below then restore the missing part of the words.}

Why the Shiites shed mournful tears at the beginning of every new Islamic year especially in Ashura which means the tenth day of (Moharam) the first month in the year?Imam Hussein for wh--- is these tears sh--- refused to b--- to the tyrant of his ti-(Yazid the son of Maawiyah). He st---- and fought to bec--- a martyr for his mis---.Imam Hussein's mis---- was and will st--- as a symbol for the fre----, dignity, and rejec--- of humiliation by all the dict--- tyrants. This is w-- Imam Hussein rema---- the symbol for fre----, dignity and val--- for all the libe---- irrespective of their reli------. Yazid was tyr----, and dictator who opp---- the people and fo---- them to bow to his wi---.

Zainab was the Hero of kerbala.Zainab is the daughter of Imam Ali Bin Abi Talib. Her mot---- is Fatima the dau---- of Prophet Mohammad. She bo--- 5 years af--- her grand father and family migr----- to Medina $(627 \mathrm{BC})$. Her grand father called her Zainab which is a desert tree that give very nice fragrant. 